\title{
Litauen und die Könige von Böhmen (von den letzten Přemysliden bis zu Karl IV.)
}

\section{Lithuania and the kings of Bohemia (from the last Přemyslides to Charles IV)}

\author{
Libor Jan / jan@phil.muni.cz \\ Historický ústav, Filozofická fakulta, Masarykova univerzita, Brno, CZ
}

\begin{abstract}
Přemysl Otakar II was the first of the Czech Premyslid kings to turn his attention to Lithuania. Incidentally, Heidenreich Bishop of Chelmno from the Order of the Teutonic Knights stayed at his court; in 1253 he crowned the Lithuanian duke Mindaugas. The king came to the aid of the Teutonic Knights against the Prussians at the turn of 1254/1255 and for the second time in $1267 / 1268$, when the eventual Christianisation of Lithuania also played an important role in his ultimately unsuccessful plans to establish a capital in Olomouc. The knightly King John of Luxembourg marched three times $(1329,1336 / 1337,1344 / 1345)$ against the Lithuanians together with the Order of the Teutonic Knights and forces from western Europe. Undoubtedly of interest is the letter of Charles IV to Grand Duke Algirdas dated 21 April 1358, when he addressed him as monarcha mundi with an offer of baptism.
\end{abstract}

\section{Keywords}

History; the Middle Ages; Kings of Bohemia; Lithuania; Teutonic Order; Crusades; Diplomacy 
Der Schwertbrüderorden oder „die Brüder der Ritterschaft Christi in Livland,“ welcher 1202 vom Bischof von Estland gegründet worden war, erlitt im Jahre 1236 eine vernichtende Niederlage von den Litauern. Ende September des genannten Jahres wurde Meister Folkvin von den Litauern bei Šiauliai (Saule) überrascht und kam mit sechzig Rittern, einer Anzahl von Dienstbrüdern, Söldnern und bewaffneten Pilgern ums Leben. Aufgrund eines Ansuchens der livländischen Brüder und der päpstlichen Zustimmung kam es Mitte Mai 1237 zur Eingliederung des livländischen Ordens in den Deutschen Orden. Der Orden weitete dadurch seinen Wirkungsbereich beträchtlich aus, erbte aber zugleich die problematischen Beziehungen zum livländischen Bischof (welche später auf den Erzbischof von Riga übertragen wurden) und zum Königreich Dänemark, welches seine territorialen Ansprüche in Westestland verteidigte. Zum Landmeister wurde zunächst Dietrich von Grüningen ernannt, welcher aber bald von dem erfahrenen Hermann Balk abgelöst wurde. ${ }^{1}$

Die Aufmerksamkeit der Deutschordensbrüder richtete sich nun auf das preußische Samland. Inzwischen nutzte der Orden aber die gespannte Situation zwischen Litauen und Samogitien und entschied sich mithilfe der großen Koalition sowie dem russischen Fürsten und den Sudauern (Jatwingern), den litauischen Fürsten Mindaugas anzugreifen. Der Bevollmächtigte des Landmeisters in Livland Andreas von Felben führte den Angriff von Norden aus, und der von zwei Flanken her gefährdete Mindaugas nahm direkten Kontakt mit dem päpstlichen Stuhl auf und nahm die Taufe an, worauf Papst Innozenz IV. Litauen unter seinen Schutz stellte und die Zustimmung zu der Königskrönung von Mindaugas gab. Dazu ist es in der Tat an der Wende vom Juni zum Juli 1253 auch gekommen, die rituelle Salbung führte der Culmer Bischof Heidenreich durch, welcher dem neuen litauischen König auch die Krone auf sein Haupt gesetzt hat. Mindaugas trat Samogitien, oder genauer gesagt den Anspruch darauf an den Orden ab. ${ }^{2}$ Der Deutsche Orden konnte sich nun vollständig auf das Samland konzentrieren.

Zur endgültigen Demütigung dieses Landes dürfte auch Přemysl Ottokar II. beigetragen haben, welcher erst kurz zuvor König von Böhmen geworden war (1253, vorher war er bereits Herzog von Österreich und Markgraf von Mähren), aber einer durchaus unangenehmen ungarisch-polnisch-galizischen Koalition seiner Feinde die Stirn bieten musste. Der Feldzug nach Preußen hatte für ihn Prestigecharakter mit den zu erwartenden politischen Auswirkungen - Stärkung seiner Stellung bei der päpstlichen Kurie. Mit dem Feldzug hing möglicherweise bereits der Aufenthalt des ersten Bischofs von Erm-

1 Petri de Dusburg Chronica terrae Prussiae. Ed. Max Töppen. Scriptores rerum Prussicarum I. Leipzig 1861, S. 65-66; Petrus de Dusburgk: Chronica terrae Prussiae = Piotr z Dusburga: Kronika ziemi pruskiej. Monumenta Polonia Historica. Nova Series = Pomniki dziejowe Polski. Seria II, t. XIII. Cracoviae/Kraków 2007, S. 47, 49; Hartmanns von Heldrungen Bericht über die Vereinigung des Schwertbrüderordens mit dem Deutschen Orden und über der Erwerbung Livlands durch den letztern. Ed. Theodor Hirsch. Scriptores rerum Prussicarum V. Leipzig 1874, S. 168-172; Biskup, Marian - LabudA, Gerard: Dzieje Zakonu krzyżackiego w Prusach. Gospodarka - Społeczeństwo - Państwo - Ideologia. Gdańsk 1986, S. 131-132; Biskup, Marian: Uformowanie sie duchownych wtadztw terytorialnych w średniowiecznych Inflantach i ich granice panstwowe. In: Inflanty w średniowieczu. Władztwa zakonu krzyżackiego i biskupów. Red. Marian Biskup. Toruń 2002, S. 12-13; Dorna, Maciej: Bracia zakonu krzyżackiego w Prusach w latach 1228-1309. Studium prozopograficzne. Poznań 2004, S. 223.

2 Biskup, M. - Labuda, G.: Dzieje Zakonu, S. 148; Gouguenheim, Sylvain: Krzyżacy. Malbork 2012, S. 140. 
land (lat. Warmia) Anselm in Mähren Ende des Jahres 1253 zusammen - Anselm suchte zweifelsohne, sich dem König vermittels des Olmützer Bischofs Bruno von Schaumburg zu nähern. ${ }^{3}$ Mit Sicherheit hing der Aufenthalt des Hochmeisters des Deutschen Ordens Poppo von Osterna in Böhmen im September des Jahres 1254 mit dem geplanten Kreuzzugsunternehmen zusammen. ${ }^{4}$ Auch der Papst war im November damit einverstanden, dass der König von Böhmen, princeps christianissimus et strenuus athleta Christi, zum Anführer eines neuen Kreuzzugsunternehmens sein wird. ${ }^{5}$

Přemysl Ottokar II. zog laut den Annales Ottakariani am 14. Dezember 1254 aus, um für ein Paar Tage in Breslau halt zu machen, wobei dieser Ort zweifellos als Treffpunkt der Pilger aus Sachsen, Thüringen, Meißen und Rheinland bestimmt war, während die Böhmen, Mährer und Österreicher mit dem König gezogen sind. Hier schloss sich auch einer der Markgrafen von Brandenburg, der Neffe des Königs Otto III., der Pilgerschar an. Nach Weihnachten, das sie in Breslau gefeiert haben, zog das Heer, welches laut Dusburg etwa 60 tausend Bewaffnete zählte, weiter nach Norden. Ihr Ziel war Elbing, der damalige Sitz des Landmeisters, wo es zum Streit eines Sachsen mit einem Österreicher um den Vorrang beim Mehlmahlen kam, woraus angeblich eine große bewaffnete Auseinandersetzung entflammt wäre, wenn der Olmützer Bischof den Streit nicht im letzten Moment geschlichtet hätte. Außer Bischof Bruno befanden sich auch der Kulmer Bischof Heidenreich sowie der Bischof von Ermland Anselm in der königlichen Gefolgschaft. Danach zog das Heer zur Ordensburg Balga, wo die Brüder einen preuBischen Greis namens Gedune vor den König geführt haben, den Vater von Vyšegaud von Medenau, aus dem Geschlecht der ruhmvollen Krieger von Samland. Dieser habe über Přemysls Gefolgschaft geblickt, bei dem es sich zweifelsohne nur um einen kleinen Vortrupp handelte, und verlautbart, dass mit einem dermaßen kleinen Heer im Lande nichts zu erreichen sei. Dies wiederholte sich als weitere Heeresteile gekommen waren. Erst nachdem das ganze Kreuzfahrerheer zusammengekommen war, äußerte Gedune die Meinung, dass der König nun ins Samland ziehen könne wohin es ihm gefalle: „du wirst erlangen, was du willst.“ Přemysl übergab dann dem Greis seine Banner, um sie an seine Güter und die Wohnstätten seiner Verwandten zu befestigen, damit diese verschont bleiben. Dieser zögerte aber alles in allem, und die ungeduldigen Deutschen haben seine Habe verbrannt und die Verwandten erschlagen samt seines Bruders Ringelus. Danach betrat der König mit seinem ganzen Heer das Samländer Gebiet von Medenau, verbrannte alles, was er konnte und erschlug oder nahm viele Leute gefangen. Am folgenden Tag kamen die preußischen Adeligen im Gebiet von Rudau, welches von den Kreuzfahrern belagert wurde, zu ihm und haben ihn darum ersucht, ihr Volk zu

3 Codex diplomaticus et epistolaris regni Bohemiae (= CDB) V-1. Edd. Jindřich Šebánek - Sáša Dušková. Pragae 1974, Nr. 11, S. 47-49; zu Anselm vgl. Die Bischöfe des Heiligen Römischen Reiches 1198 bis 1448. Ein biographisches Lexikon. Hg. v. Erwin Gatz u. Clemens Brodkorb. Berlin 2001, S. 181.

4 Der Aufenthalt des Hochmeisters in Böhmen, wahrscheinlich auch in Prag, ist nur belegt in der Datierungsformel (Datum Bohemie) der Bevollmächtigung des deutschen Landmeisters Dietrich von Grüningen zur Verhandlung in der Streitsache der livländischen Brüder mit dem Erzbischof von Riga - Preußisches Urkundenbuch (= PUB). Politische Abtheilung. Bd. I.1. Die Bildung des Ordensstaats. Hg. v. Rudolf Philippi u. Carl Peter Woelky. Königsberg i. Pr. 1882, Nr. 294, S. 219.

$5 \quad$ PUB I.1, Nr. 296-297, S. 220-222. 
verschonen. Danach besetzte er die Regionen Quednau, Waldau, Kaimen und Tapiau und wählte Geiseln aus, wodurch die Gehorsamkeit der preußischen Bevölkerung gegenüber dem neuen Glauben und den Ordensbrüdern gesichert werden sollte. Der König selbst sollte als Pate die Taufe eines bedeutenderen Preußen begleiten, welcher nach ihm den Namen Ottokar bekam, ähnlich wie z. B. Otto von Brandenburg; die Taufen führte der Olmützer Bischof mit zwei seiner preußischen Kollegen durch. Danach erreichte der König von Böhmen einen bestimmten Ort auf einem Berg, wo er den Brüdern den Rat gab, hier zum Schutze des Glaubens eine Burg zu erbauen und hinterließ ihnen zu diesem Zweck zahlreiche Geschenke. Im Jahre 1255 sind die Ordensbrüder an der Spitze ihres Heeres und der getauften Preußen hierhergekommen und haben eine Burg an dem Ort erbaut, welcher später Alte Burg genannt wurde, die sie dann zu Ehren des Königs Kunigsbergk - also Königsberg - genannt haben. Die Preußen nannten diesen Ort aber nach dem dortigen Wald Tuwangste. ${ }^{6}$

Wahrscheinlich nicht lange nach und bestimmt im Zusammenhang mit dem Eroberungszug, der zweifelsohne als peregrinatio contra paganos gewertet werden kann, ist eine erst relativ kürzlich in der Bibliothek des Trinity College in Dublin entdeckte geographische Schrift entstanden, die unter dem Namen Descripciones terrarum bekannt ist. Bei ihr handelt sich um eine Beschreibung der Gebiete des nordöstlichen Europas im Kontext der Christianisierungstätigkeit, welche auf keinen Fall die Sichtweise der Deutschordensritter wiedergibt - ihr Verfasser war wahrscheinlich in den Jahren 1255-1260 ein Ordensbruder aus dem Orden der Dominikaner oder Minoriten (die neueste Identifizierung erwägt überzeugend einen Minoritenbruder Bartholomäus von Prag), welcher sich im Rahmen der päpstlichen Politik in den gegebenen, bislang heidnischen Gebieten engagierte. Der Verfasser nahm an dem militärischen Zug von Přemysl Ottokar II. teil, von dem er berichtet, gleichzeitig erinnert er daran, dass er Zeuge der königlichen Patenschaft des bedeutenden preußischen Adeligen war. Er spricht auch von der Taufe von Mindaugas (1251) und seiner Krönung (1253), an der er ebenfalls teilnahm, erwähnt aber nicht mehr die Apostasie des litauischen Königs in den Jahren 1260-1261 und seinen darauffolgenden Tod. Er kennt die friedliche Tätigkeit des ersten preußischen Bischofs Christian, spricht von vier preußischen und drei livländischen Bistümern und erwähnt in diesem Zusammenhang, dass der Erzbischof gerade in Livland seine Residenz hat (im Jahre 1246 ist Albert Suerbeer Erzbischof für Preußen, Livland und Estland geworden, ab 1253 residierte er in Riga als Oberhaupt der Provinz). ${ }^{7}$ Er war der erste, der über den Brauch der Preußen (was für die meisten der baltischen Völker galt) informierte, einen verstorbenen Krieger im herrlichen Gewand, in voller Rüstung und auch mit dem Pferd zu verbrennen. Er erinnert darüber hinaus an die Predigertätigkeit seines Mitbruders Vojslav im Grenzgebiet zwischen den Litauern und den Jatwingern. Obwohl es sich um eine kurz gefasste Schrift handelt, sind seine Informationen über das Baltikum als durchaus zuverlässig zu werten. ${ }^{8}$

6 Petri de Dusburg Chronica, S. 90-92; Petrus de Dusburgk: Chronica terrae Prussiae, S. 102-103; Př́běhy krále Přemysla Otakara II. Ed. Josef Emler. Fontes rerum Bohemicarum II. Praha 1874, S. 308-309.

7 Biskup, M.: Uformowanie, S. 20.

8 Edition in: Colker, Marvin L.: America rediscovered in the thirteenth century? Speculum 54, 1979, S. 720-726; 
Die Herrschaft der Deutschordensritter in Preußen war, obwohl es so scheinen könnte, nicht stabil. 1260 begann ein weiterer preußischer Aufstand, welcher die nächsten 23 Jahre bis 1283 in Anspruch nahm. Der Orden büßte einige Festungen ein, manche andere wurden verbrannt, darunter auch das neugegründete Königsberg. Die Ordenstruppen erlitten manche empfindliche Niederlagen, außer den Pomesaniern vereinigten sich alle preußischen Stämme zwischen Weichsel und Memel: die Nadrauer, Skalen, Samländer, Barter, Sudauer (Jatwinger). Der Krieg nahm einen totalen Charakter an, wobei die „Taktik der verbrannten Erde“ zur Anwendung kam. Der Orden machte mobil, und nach Preußen zogen Kriegerschaaren deutscher Grafen, Markgrafen und Herzöge. Mit ihrer Hilfe sowie mit einer technologischen Überlegenheit und darüber hinaus mithilfe von vielen gut befestigten Burgen ist es dem Orden gelungen, den Widerstand zu brechen, damit gegen Litauen eine neue Offensive gestartet werden konnte. ${ }^{9}$

An der Jahreswende 1267/1268 begab sich auch der König von Böhmen wieder nach Preußen. Sein Bemühen hing aber diesmal vielmehr mit einem weitreichenden kirchenpolitischen Plan zusammen, an dem auch der Olmützer Bischof Bruno wesentlich beteiligt war. Der König und der Bischof begannen bereits im Herbst mit dem Orden Verhandlungen darüber zu führen, Přemysl die bestehenden oder abgefallenen Gebiete Preußens im Austausch gegen die Unterstützung von Galinden, Jatwingen und Litauen zu garantieren. Bei der Kurie wurde inzwischen die Forderung gestellt, die neugewonnenen Gebiete dem König von Böhmen und in kirchlicher Hinsicht dem Olmützer Bischof zu unterstellen, wobei Olmütz zur Metropole erhoben werden sollte. Papst Clemens IV. hat in einer Urkundenserie vom 20. Januar 1268 die böhmischen Forderungen abgelehnt; dem König hat er lediglich erlaubt, in den eroberten Gebiete einen königlichen Stuhl zu errichten und die eroberten Gebieten unter seiner Verwaltung zu behalten, er untersagte die Erhebung von Olmütz, denn sonst würde dem Mainzer Erzbischof Schaden entstehen; er billigte lediglich die geistliche Verwaltung der gewonnenen Gebiete durch Bruno, jedoch nur Galinden und Jatwingen, solange nicht anders entschieden wird. ${ }^{10}$ Der König von Böhmen zog anscheinend in einer ähnlichen Jahreszeit wie im Falle des ersten militärischen Feldzugs nach Preußen. Bei Kulm war er am 3. Januar 1268 bei der Vermittlung des Abkommens zwischen dem Ordensrepräsentanten, dem preußischen Landmeister Ludwig von Baldersheim und dem Fürsten von Pommerellen

vgl. Spotkanie dwóch światów. Stolica apostolska a świat mongolski w potowie XIII wieku. Relacje powstałe w związku z misją Jana di Piano Carpiniego do Mongołów. Red. Jerzy Strzelczyk. Poznań 1993, S. 107108, 289-301 (Übersetzung ins Polnische und Kommentar); KARCZEwSKI, Dariusz: Franciszkanie w monarchii Piastów i Jagiellonów w średniowieczu. Powstanie - Rozwój - Organizacja wewnętrzna. Kraków 2012, S. 330-337; JAN, Libor: „Z nejzazšího severu, ty i mnoho lidu s tebou, všichni jezdci na koních. “ K možnostem geografických predstav premyslovského dvora ve druhé polovině 13. století. In: Cesta k rozmanitosti aneb Kavárenský povaleč digitálním historikem středověku. Sborník příspěvků k životnímu jubileu PhDr. Zdeňka Uhlíre. Edd. Renáta Modráková - Tomáš Klimek. Praha 2016, S. 139-146.

9 Biskup, M. - Labuda, G.: Dzieje Zakonu, S. 180-185; Gouguenheim, S.: Krzyżacy, S. 180-185.

10 CDB V-2, Nr. 514, S. 60-61; Nr. 538-542, S. 96-103; Petri de Dusburg Chronica, S. 134; vgl. Goll, Jaroslav: Čechy a Prusy ve středověku. Praha 1897, S. 32-37; NovotnÝ, Václav: Rozmach české moci za Přrmysla II. Otakara (1253-1271). Praha 1937 (= České dějiny I.4), S. 154-164. 
Mestwin (Mstivoj) behilflich. ${ }^{11}$ Bei Thorn kam es, nachdem die meisten Krieger die zugefrorene Weichsel bereits überquert hatten, zu einer gewaltigen Erwärmung, wegen des Tauwetters wurde auch das Heer getrennt, was die ganze Idee vereitelte und der Přemyslide die Anweisung zur raschen Rückkehr gab, insbesondere als ihn direkte Nachrichten vom grundlegenden Misserfolg seines Projektes bei der Kurie erreichten. ${ }^{12}$

Auch der Sohn von Přemysl Wenzel II. (1283-1305) unterstützte den Deutschen Orden in seinen Aktivitäten (und vice versa). Jedoch gibt es keine Nachrichten von einer direkten militärischen Unterstützung des Ordens. Der Orden engagierte sich hingegen bei Wenzels Kampf gegen Władysław I. Ellenlang oder gegen den Rügener Fürsten, welcher in Pommerellen ausgebrochen war. ${ }^{13}$

Die Haltung der nächsten Dynastie auf dem böhmischen Thron, der Luxemburger, war keinesfalls so eindeutig wie im Falle ihrer přemyslidischen Vorgänger. Johann der Blinde betrachtete den Orden als seinen natürlichen Verbündeten gegen das Polen von Władysław Ellenlang; vordergründig ging es um die Wahrung der böhmischen Interessen in Schlesien und der Belange des Ordens in Pommerellen. Er unterstützte den Orden auch durch drei Heereszüge gegen Litauen, was aber im Wesentlichen auf der ritterlichen Eigenschaft des Königs beruhte - diese fanden in den Jahren 1329, 1337 und 1345 statt. In den 20er Jahren des 14. Jahrhunderts kann allerdings eine Beteiligung von böhmischen Adeligen an den Heereszügen nach Litauen beobachtet werden. So zogen z. B. im Jahre 1323 Bernhard von Zinnburg/Cimburk und Friedrich von Egerberg mit vielen anderen Adeligen nach Litauen, im Jahre 1324 dann Peter von Rosenberg mit seinem Verwandten Hermann und einer zahlenmäßig starken Gefolgschaft. ${ }^{14}$

1329 begab sich Johann von Luxemburg selbst mit dem Herzog Boleslaus von Oppeln-Ratibor (von Falkenberg) und den Grafen von Leiningen, von Öttingen, von Neuhar, von Weilnau, von Hanau, von Württenberg, von Schaunberg und von Falkenstein, wie auch mit vielen anderen Adeligen, nicht nur aus Deutschland, sondern auch aus England nach Litauen. Sie wurden auch von vielen bedeutenden böhmischen Herren begleitet, wie etwa von Peter von Rosenberg, der Erfahrungen von seiner eigenen vorherigen Fahrt hatte; ferner sind Heinrich der Jüngere von Leipa, Wilhelm von Landstein, Thimo von Kolditz, Otto von Bergow und weitere mehr zu nennen. Mit den starken Ordenstruppen belagerte das Heer unter der Führung von Werner von Orseln die Burg oder besser gesagt den Burgwall von Samogitien Medwegalis (lit. Medwiagoia). Über den Feldzug berichtete in seinem viel später erschienenen Werk Le confort d'ami auch der bekannte Dichter Guillaume de Machaut, welcher sich in der Gefolgschaft des Königs

11 CDB V-3, Nr. 1413, S. 276-277; PUB I.2, Nr. 278-281, S. 196-199.

12 Petri de Dusburg Chronica, S. 113-114, 250-251; Goll, J.: Čechy a Prusy, S. 35-37; Novotný, V.: Rozmach české moci, S. 160.

13 Dazu am neuesten Jan, Libor: Václav II. Král na střibrném trůnu. Praha 2015, S. 292-295. Vgl. auch ŚLIWIŃSKI, Błażej: Pomorze Wschodnie w okresie rzadów księcia polskiego Wtadystawa Łokietka w latach 13061309. Gdańsk 2003, S. 67; POWIERSKI, Jan: Studia nad polityka Krzyżaków i ich sasiadów w początkach XIV wieku, cz. 2. In: Władcy, mnisi, rycerze. Ed. Błażej Śliwiński. Gdańsk 1996, S. 157-158, 168-169.

14 Petri de Dusburg Chronica, S. 258, 261; Petrus de Dusburgk: Chronica terrae Prussiae, S. 261. Vgl. Goll, J.: Čechy a Prusy, S. 59-63; SeIBt, Ferdinand: Karl IV. Ein Kaiser in Europa 1346 bis 1378. München 1978, S. 98. 
befand. ${ }^{15}$ Die Bewohner haben sich schließlich dem Kreuzfahrerheer unterworfen und viele von ihnen (die Zahl 6000 ist aber anscheinend übertrieben) sollten getauft worden, danach aber vom Glauben abgefallen sein. ${ }^{16}$ In der gegebenen Situation wollten sie durch die Taufe vermutlich aber ihr Leben retten. Bei seiner Rückkehr verhandelte der König von Böhmen mit dem Hochmeister über ein Bündnis gegen Ellenlang und auch gegen die Litauer, was eine gegenseitige Unterstützung einbrachte.

Zum nächsten Heereszug von Johann nach Preußen und gegen die Litauer, diesmal auch mit seinem Sohn Karl, kam es an der Wende der Jahre 1336 und 1337. Die politische Situation hatte sich in der Zwischenzeit wesentlich verändert. An dem Visegráder Treffen zu 1335 handelte Johann ein Bündnis mit dem neuen polnischen König Kasimir dem Großen und dem ungarischen König Karl Robert aus. Zugunsten von Kasimir verzichtete er auf seine Ansprüche auf die polnische Krone (als Erbschaft der Přemysliden), und der Piaste machte im Gegenzug dazu keine Ansprüche mehr auf Oppeln und auf weitere schlesische Gebiete geltend. Auf einem weiteren Treffen im ungarischen Visegrád vermittelte Johann die Vereinbarung zwischen dem Deutschen Orden und dem polnischen König, gemäß welcher der polnischen Krone die vom Orden beanspruchten Gebiete, nämlich das Dobriner Land und Kujawien zufielen, während Pommerellen dem Orden in den ursprünglichen Grenzen zuerkannt wurde. Die erwähnte Koalition war dann insbesondere gegen die Habsburger gerichtet, beziehungsweise auch gegen den Kaiser Ludwig den Bayern. ${ }^{17}$ Nicht nur aus Böhmen, sondern auch aus dem Reich hat ein großes Herr zum Jahresende 1336 seine Schritte in Richtung Preußen gelenkt. Wenn wir einmal von der obligatorischen Natur der Ritterfahrt gegen die Heiden absehen, sind die eigentlichen Ursachen des Heereszuges jedoch nicht besonders klar. Der Heereszug war von Breslau über Thorn nach Königsberg in das Gebiet des Kurischen Haffes gerichtet. Von hier aus sollte das Heer über Klaipéda (Memel) in Litauen einfallen. Wegen des milden Winters, in dem alle Sumpf- und Küstengebiete aufgetaut waren, war die dortige Landschaft für die Operationen eines großen Heeres im Grunde unpassierbar geworden. Der König begab sich mit weiteren Teilnehmern auf die Rückreise, mit Ausnahme von Karl, der in Königsberg zurückblieb, wo er seine Magengeschwüre auskurierte. ${ }^{18}$

15 Zajączkowski, Stanisław: Wilhelm de Machaut i jego wiadomośći do dziejów Polski i Litwy w XIV w. Kwartalnik Historyczny 43, 1929, S. 217-228. Über Machauts Tätigkeit am Hof von König Johann vgl. auch EARP, Lawrence: Guillaume de Machaut. A Guide to Research. New York - London 1995, S. 8-9, 11-14.

16 Petri de Dusburg Chronica, S. 271; Die Chronik Wigands von Marburg. Ed. Theodor Hirsch. Scriptores rerum Prussicarum II. Leipzig 1863, S. 462-463; Wigand von Marburg, Nowa kronika pruska. Edd. Sławomir Zonenberg - Krzysztof Kwiatkowski. Toruń 2017, S. 142-145; Petra Žitavského Kronika zbraslavská. Ed. Josef Emler. Fontes Rerum Bohemicarum IV. Pragae 1884, S. 293-294. Vgl. Goll, J.: Čechy a Prusy, S. 74-76; Šusta, Josef: Král cizinec. Praha 1939 (= České dějiny II.2), S. 462-476; SeibT, F.: Karel IV., S. 98.

17 Dazu Šusta, Josef: Karel IV. Otec a syn. 1333-1346. Praha 1946 (= České dějiny II.3), S. 238-246; SPĚvÁČEK, Jiří: Jan Lucemburský a jeho doba (1296-1346). K prvnímu vstupu českých zemí do svazku se západní Evropou. Praha 1994, S. 522-523; BoвкovÁ, Lenka: Velké dějiny zemí Koruny české. IV.a 1310-1402. Praha Litomyšl 2003, S. 156-160; Szczur, Stanisław: Zjazd wyszehradzki z 1335 roku. Studia Historyczne 35, 1992 , S. 3-17.

18 Život císaře Karla IV. Ed. Josef Emler. Fontes rerum Bohemicarum III. Praha 1882, S. 365-366 (cap. XVI); Petra Žitavského Kronika zbraslavská, S. 334; Die Chronik Wigands von Marburg, S. 490-491; Wigand von 
Manche Verfasser verbinden den Heereszug der Jahreswende 1336/1337 mit der Verzierung des kleineren Saals in Neuhaus (tsch. Jindřichův Hradec in Südböhmen). Dort ist die Georgslegende abgebildet, wobei sich im unteren Streifen viele Wappen befinden. Die im Grunde allgemein anerkannte Auslegung lautet, dass sowohl die Inspirationsquelle der Legende als auch der Wappen mit dem zweiten Feldzug von König Johann in Verbindung gebracht werden können. Die Wappen dürften ihren Teilnehmern gehören, und der Raum sollte vielleicht als eine Art Begegnungsort für sie dienen. Konkrete Belege fehlen aber, und es handelt sich lediglich um eine nicht sehr gestützte Hypothese. ${ }^{19}$

Die dritte Fahrt formierte sich an der Jahreswende 1344/1345 an dem üblichen Ort solcher Unternehmen, nämlich in Breslau. An ihrer Spitze standen außer Johann und Karl auch der ungarische König Karl Robert, hinzu kamen auch der burgundische Herzog, der Graf von Hennegau und weitere führende Männer des Reiches. Das gewaltige Heer vereinigte sich in Königsberg mit den Truppen des Hochmeisters Ludolf König und begab sich gen Klaipéda. Sie wurden jedoch von fälschlichen Gerüchten über einen litauischen Angriff auf Königsberg erreicht und begaben sich eilig auf den Rückzug. Inzwischen hatten die Litauer jedoch die ungeschützten Gebiete von Livland verwüstet. Ähnlich wie im Falle des ersten Feldzuges wurden die Krieger vom Wetter überrascht; das Eis taute auf und die Bewegung eines großen Heeres war unmöglich. ${ }^{20}$

Interessant ist die Haltung, die Karl IV., der natürlich nicht nur für die böhmische Politik von grundlegender Bedeutung war, gegenüber den Deutschordensrittern einnahm. Karl verfolgte eine unterschiedliche Politik gegenüber dem Orden im Reich, wo der deutsche Landmeister Wolfram von Nellenburg als höchster Repräsentant des Ordens tätig war. Dieser Stand zunächst auf der Seite von Ludwig dem Bayern, nach dessen Tod wechselte er aber zur Seite Karls über. Zu einer positiven Wendung in diesem Zweig des Ordens kam es anscheinend während der Teilnahme des Mergentheimer Komturs, späteren Landkomturs in Franken und anschließenden Landmeisters Philipp von Bickenbach an Karls Romreise in den Jahren 1354 und 1355. Eine weitere Einheit des Ordens stellte die böhmisch-mährische Ballei dar, welche als Kammerballei des Hochmeisters galt und insgesamt als Gründungswerk der Vorfahren Karls, also der Přemysliden, zu betrachten ist. Hier hat sich aber die Herrscheraktivität im Jahre 1348 durch die Bestätigung des Immunitätsprivilegs Přemysl Ottokars II. von 1222 erschöpft. Den dritten Bereich stellte Preußen selbst und seine Führung dar. Wie es Udo Arnold

Marburg, Nowa kronika pruska, S. 200-203. Dazu vgl. ŠustA, J.: Karel IV. Otec a syn, S. 236-237, 245-246; SPĚVÁČEK, J.: Jan Lucemburský a jeho doba, S. 530.

19 Vgl. dazu die Beiträge des Sammelbandes Sankt Georg und sein Bilderzyklus in Neuhaus/Böhmen (Jindřichưv Hradec). Historische, kunsthistorische und theologische Beiträge. Hg. v. Ewald Volgger. Marburg 2002 (= Quellen und Studien zur Geschichte des Deutschen Ordens 57), hier vor allem JiRásko, Luděk: Die Deutschordenskommende Neuhaus im Mittelalter, S. 6-33, und Nový, Rostislav: Die Wappengalerie auf Schloss Neuhaus aus dem Jahre 1338, S. 34-47. Novýs Identifizierung des rechten der beiden Donatoren mit der Inschrift HR.MAN DUNHRRE als Hermann, „einen Vertreter der Kommende, den Komtur, und zugleich einen Kanoniker (DUNHRRE sollte nach ihm „Domherr“ bedeuten- Anm. L. J.) des Ordens, aller Wahrscheinlichkeit nach zugehörig zum Landesordenskapitel der böhmischen Ballei“ (ibidem, S. 42), ist ganz unwahrscheinlich und zeigt, dass der Verfasser die innere Struktur des Deutschen Ordens nicht gekannt hat.

Die Chronik Wigands von Marburg, S. 504-505; Wigand von Marburg, Nowa kronika pruska, S. 226-229. 
zutreffenderweise wertete, haben es die Deutschordensritter zwar geschafft, in Preußen einen selbstständigen Staat aufzubauen, der aber in Karls politischen Visionen vielmehr ein fremdes Element darstellte, da der Luxemburger hier kaum seine für ihn typische Politik zur Anwendung bringen konnte, denn diese beruhte auf dynastischen Beziehungen. ${ }^{21}$

Karl beteiligte sich aber noch einmal an dem Geschehen, welches Litauen und die Interessen der Deutschordensritter unmittelbar betraf. Ab 1350 intensivierten sich die Angriffe der Litauer auf die polnischen Grenzgebiete, was den polnischen König in dem Kampf und den Streitigkeiten mit weiteren Nachbarn erschöpfte, vor allem aber mit dem Deutschen Orden. Kasimir der Große begann deswegen mit Hilfe von Innozenz VI. ein politisches Spiel, denn der Papst hatte enge Beziehungen zu Karl, die noch auf seiner Pariser Jugendzeit basierten. Der König von Polen entsendete eine Gesandtschaft mit der Information nach Avignon, dass die Litauer bereit sind, die Taufe anzunehmen. Dasselbe teilte der erfahrene Ordensritter Heinrich von Plauen dem Kaiser mit. Ob die Deutschordensritter in der Zwischenzeit mit den litauischen Fürsten verhandelt haben, oder umgekehrt Karl mit dem Papst und Kasimir, bleibt uns verborgen. Am 21. April 1358 wandte sich Karl aus Prag mit einem Schreiben an den Großfürsten (wahrscheinlich Olgerd/Algirdas) und an weitere Fürsten (Illustribus et Magnificis Principi et eius fratribus ducibus Lyuonie - sic?!) als monarcha mundi mit der Aufforderung zur Taufe und der Zusage von Freiheiten. ${ }^{22}$ Die im Grunde bejahende Antwort sollte von der litauischen Gesandtschaft dem Kaiser in Nürnberg überbracht werden. ${ }^{23}$ Sie kehrten mit der Zusicherung zurück, dass Karl eine Gesandtschaft mit dem Prager Erzbischof Ernst von Pardubitz, dem Herzog Nikolaus von Troppau und dem deutschen Landmeister Wolfram von Nellenburg an der Spitze nach Litauen entsenden wird. Die Gesandtschaft begab sich über die Ordenszentrale zum Großfürstenhof; vielleicht wurde gerade dort die Taufe der litauischen Fürsten zu Weihnachten in Breslau ausgehandelt. Diese fand aber schließlich nicht statt, zweifelsohne wegen der zurückhaltenden Stellungnahme des Hochmeisters Winrich von Kniprode und wegen seiner Unwilligkeit auf manche litauische Forderungen einzugehen, welche die Abtretung von großen Gebieten in Preußen und Livland umfassten, wobei diese Forderungen in die Friedensverhandlungen zwischen dem Orden und Litauen miteinbezogen werden sollten. ${ }^{24}$ Trotzdem wurde 1365

21 Arnold, Udo: Preußen, Böhmen und das Reich - Karl IV. und der Deutsche Orden. In: Kaiser Karl IV. Staatsmann und Mäzen. Hg. v. Ferdinand Seibt. München 1978, S. 169, 172-173. Siehe auch Hellmann, Manfred: Karl IV. und der Deutsche Orden in den Jahren 1346-1360. Folia diplomatica 1, 1971, S. 105-112; JÄHNIG, Bernard: Der Deutsche Orden und Karl IV. In: Kaiser Karl IV. 1316-1378. Forschungen über Kaiser und Reich. Hg. v. Hans Patze. Göttingen 1978, S. 103-150.

22 Die Edition des Briefes, der im National-Museum in Warschau immer noch als Original existiert, hat Herbert Grundmann besorgt - Grundmann, Herbert: Das Schreiben Kaiser Karls IV. an die heidnischen LitauerFürsten 1358. Folia diplomatica 1, 1971, S. 91-93.

23 Ibidem, S. 95.

24 KavkA, František: Vláda Karla IV. za jeho císařstvi (1355-1378). Země České koruny, rodová, říšská a evropská politika I (1355-1364). Praha 1993, S. 121-128; Borovský, Tomáš: Jan Lucemburský, Karel IV. a Litva = John the Blind of Bohemia, Charles IV and Lithuania. In: Svět tajemných Baltů = The World of the Mysterious Balts. Edd. Libor Jan - Petr Kostrhun - Zdeňka Nerudová. Brno 2013, S. 135-136. 
einer der Söhne von Kejstut getauft, welcher sich dann vielleicht bis 1377 am Kaiserhof aufhielt. ${ }^{25}$

Die Politik von Karl wurde in diesen Jahren wahrscheinlich von dem Umstand diktiert, dass der König von Polen keinen männlichen Nachkommen hatte, und wenn die Beziehungen zwischen beiden Herrschern auch kompliziert waren, war die Möglichkeit, aus einer dynastischen Verbindung zu profitieren, für Karl immer verlockend.

\section{Litva a čeští králové (od posledních Přemyslovců ke Karlu IV.)}

Jako první z českých přemyslovských králů obrátil k Litvě svoji pozornost Přemysl Otakar II. Na jeho dvoře mimochodem pobýval chelmský biskup z řádu německých rytířu Heidenreich, který v roce 1253 korunoval litevského knížete Mindaugase. Král vytáhl na pomoc řádu německých rytířu proti Prusům poprvé na přelomu let 1254/1255. Pravděpodobně nedlouho po výpravě, kterou lze hodnotit zcela jistě jako peregrinatio contra paganos, a určitě v souvislosti s ní vznikl relativně nedávno objevený geografický spisek nalezený v knihovně Trinity College v Dublinu, známý pod názvem Descripciones terrarum. Jde o popis krajů severovýchodní Evropy v souvislosti s christianizační činností, který rozhodně nesleduje východiska řádu německých rytíŕu - autorem byl pravděpodobně v letech 1255-1260 dominikánský nebo minoritský řeholník (nejnovější identifikace uvažuje přesvědčivě o představiteli minoritů Bartolomějovi z Prahy), který se angažoval v rámci papežské politiky v uvedených, dosud pohanských krajích. Autor se zúčastnil výpravy Přemysla Otakar II., o níž hovoří, a připomíná, že byl svědkem králova kmotrovství významného pruského předáka. Hovoří také o Mindaugasově křtu (1251) a jeho korunovaci (1253), jíž se také zúčastnil, nezaznamenává však již apostazi litevského krále v letech 1260-1261 a jeho následnou smrt. Zná pokojnou misijní činnost prvního pruského biskupa Christiana, hovoří o čtyřech pruských a třech livonských biskupstvích, s tím, že právě v Livonsku (Rize) reziduje arcibiskup.

Podruhé Přemysl Otakar II. táhl na pomoc řádu německých rytírů na přelomu let 1267/1268. Král a olomoucký biskup Bruno zahájili již na podzim jednání s řádem, kterému Přemysl zaručil stávající či odpadlá území Pruska výměnou za podporu v získání Galindie, Jatvingie a Litvy. U kurie byl zatím vznesen požadavek podřídit nově získané kraje českému králi a v církevním ohledu olomouckému biskupovi, přičemž Olomouc měla být povýšena na metropoli. Papež Kliment IV. nicméně sérií listin z 20. ledna 1268 české požadavky odmítl. Hned třikrát (1329, 1336/1337, 1344/1345) táhl proti Litevcům spolu s řádem německých rytíruo a oddíly ze západní Evropy rytîršsḱ král Jan Lucemburský. Na těchto i dalších výpravách se výrazně podílela i česká šlechta. Existují názory, že s Janovou druhou výpravou souvisejí šlechtické erby doplňující legendu o sv. Jiří vymalované v malém sále nejstaršího paláce jindřichohradeckého zámku.

Nepochybně zajímavý moment představuje dopis z 21. dubna 1358, kdy se Karel IV. obrátil z Prahy svým listem na velkoknížete Olgerda a další litevská knížata jako monarcha mundi s výzvou ke křtu i př́íslibem svobod. V zásadě kladnou odpověd' mělo přinášet litevské poselstvo císaři do Norimberku. Zpět s sebou odváželo př́ílib, že Karel vyšle na Litvu poselstvo v čele s pražským arcibiskupem Arnoštem z Pardubic, vévodou Mikulášem II. Opavským a německým zemským

25 SEIвt, F.: Karel IV., S. 377; Borovský, T.: Jan Lucemburský, S. 136. 
mistrem Wolframem z Nellenburgu. Poselstvo se vypravilo přes řádovou centrálu (Malbork) k velkoknížecímu dvoru; snad právě tam byl sjednán křest litevských knížat na Vánoce ve Vratislavi. K události však nakonec nedošlo, nepochybně pro rezervovaný postoj tehdejšího velmistra Winricha z Kniprode a jeho neochotu přistoupit na některé litevské požadavky, týkající se odstoupení rozsáhlých území v Prusku a Livonsku, které měly být pojaty do mírových jednání mezi řádem a Litvou. 
